\title{
In memoriam Hans Ernst Ott
}

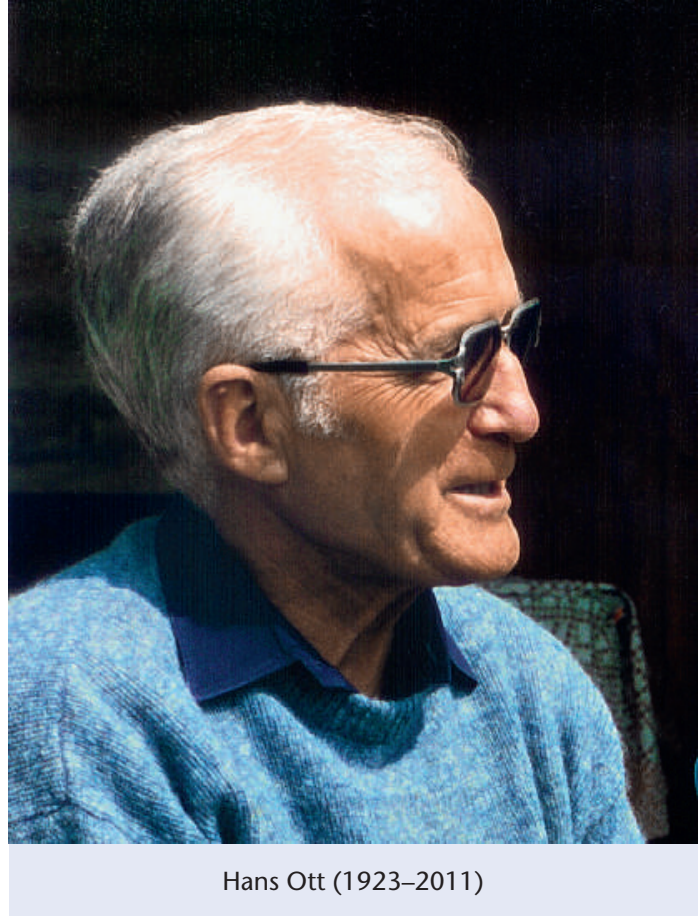

Nach einer langen Leidenszeit ist Fürsprecher Hans Ott, wie wir ihn in der FMH nannten, am 6. Oktober einer hartnäckigen Krankheit erlegen, welche die letzten Monate seines Lebens verdüstert hat. Wir werden uns stets mit Dankbarkeit und Respekt an ihn erinnern und sprechen seiner Familie und seinen Angehörigen unsere herzliche Anteilnahme aus.

Hans Ott hat der FMH knapp 18 Jahre seines Lebens gewidmet. Nachdem er sich während einiger Monate unter der Anleitung seines Vorgängers, des Fürsprechers Hermann Egli, mit seinen bevorstehenden Aufgaben vertraut gemacht hatte, übernahm er die Funktion des Generalsekretärs. Er erfüllte seine Aufgaben gründlich, effizient und mit der hohen Kompetenz, die schon jene Personen in ihm erkannt hatten, die ihn in die Position des Generalsekretärs berufen hatten. Sie wurden nicht enttäuscht.

Mit seinen Aufgaben innerhalb der FMH wurde Hans Ott in einer Zeit betraut, in der das Umfeld der Gesundheitspolitik und demzufolge auch die Bedingungen für die Standespolitik zunehmend härter und anspruchsvoller wurden. In enger Zu- sammenarbeit mit den aufeinanderfolgenden Präsidenten Jean Bergier, Karl Zimmermann und Hans-Ruedi Sahli gelang es ihm, das Schiff FMH auf dem richtigen Kurs zu halten. In diesem $\mathrm{Zu}-$ sammenhang ist darauf hinzuweisen, dass der Kapitän bereits über einen wertvollen Erfahrungsschatz verfügte, den er in verschiedenen verantwortungsvollen Positionen erworben hatte. Dazu gehörten seine Tätigkeit im familieneigenen Verlagshaus, als Jurist bei einem multinationalen Schweizer Grossunternehmen, als angesehener Präsident des Thuner Gerichts und als Grossrichter eines Divisionsgerichts. Seinen Berner Juristenkollegen war seine hohe Fachkompetenz ebenfalls aufgefallen, denn sie hatten ihn in ihren Vorstand berufen und anschliessend zu ihrem Präsidenten gewählt.

Seine Analysefähigkeit, seine Gewissenhaftigkeit und seine Entschlussfreudigkeit waren für den Zentralvorstand eine wertvolle Hilfe. In zahlreichen bedeutenden eidgenössischen Kommissionen vertrat er die Interessen der Ärzteschaft. Dabei ging es insbesondere um die immer wieder unternommenen und auch heute noch nicht abgeschlossenen Versuche, in der Schweiz eine Krankenversicherung zu realisieren, die unseres Landes würdig ist. Für den freisinnigen Hans Ott, der klare Überzeugungen hatte, war dies oftmals mit der Erkenntnis verbunden, dass die «demokratische Frustration» leider auch zu den Spielregeln gehört, insbesondere wenn man fest davon überzeugt ist, die «richtige» Lösung $\mathrm{zu}$ vertreten, und diese schliesslich abgelehnt wird... Auch in diesem Bereich verfügte Hans Ott dank entsprechender Erfahrung über die notwendigen persönlichen Ressourcen, um Enttäuschungen dieser Art zu überwinden. Denn er hatte sehr konkret am politischen Leben seiner Stadt teilgenommen, indem er während vieler Jahre Mitglied des Stadtrats von Thun gewesen war.

Fürsprecher Hans Ott, der vor 24 Jahren in den Ruhestand getreten ist, hat in der Geschichte der FMH seine Spuren hinterlassen. Ein grosser Teil der von ihm ausgebrachten Saat trägt noch heute Früchte. Die Ältesten unter uns können sich sicher noch daran erinnern, dass es zu einem beträchtlichen Teil seinen Fähigkeiten zu verdanken war, dass die FMH uneingeschränkt von den sich damals bietenden Gelegenheiten profitieren und das 
«Domus medica», in dem die Büros der FMH auch heute noch untergebracht sind, zu einem vorteilhaften Preis erstellen lassen konnte. $\mathrm{Zu}$ diesen Fähigkeiten zählten sein Organisationstalent, seine Effizienz und seine Kompetenz, eine sich bietende Chance unverzüglich zu nutzen. Ein weiterer nach wie vor bestehender Beleg für das ergebnisreiche Wirken von Hans Ott, der über ein ausgeprägtes diplomatisches Geschick und über grosses Verhandlungstalent verfügte, ist die Einrichtung der Gutachterstellen für Fälle von Ärztehaftpflicht, bei der er von den Privatversicherern unterstützt wurde. Es herrscht wohl Einigkeit darüber, dass die Einrichtung dieser Institutionen, deren Dienste nach wie vor von Patienten, Anwälten und Ärzten in Anspruch genommen werden, im Bereich der betreffenden Rechtsstreitigkeiten zu einer gewissen Entspannung geführt hat.

Erwähnt werden könnten auch noch die Erfolge, die er an der Seite der verschiedenen FMHPräsidenten in zahlreichen internationalen medizinischen Organisationen erzielte, in denen er die FMH würdig vertreten hat, indem er ihr ein Publikum verschaffte, das weit über ihren Beobachterstatus hinausging. Kurz gesagt hat es Fürsprecher Hans Ott mehr als verdient, dass ihn die FMH in dankbarer Erinnerung behält.

Doch ein Mann sollte nicht nur nach seinen Taten, sondern in erster Linie anhand seiner Persönlichkeit beurteilt werden. Sowohl für Hans Ott selbst als auch für alle, die das Privileg hatten, ihn zu kennen oder mit ihm zusammenzuarbeiten, war es von Vorteil, dass er sich nie auf die Eindimensionalität seiner Funktionen beschränken liess. Dies war seiner vielseitigen Persönlichkeit und der Vielzahl seiner Interessen zu verdanken. Die Kultur und das geistige Leben bereicherten seinen Lebensweg und waren für ihn ein Ausgleich zu den belastenden Herausforderungen, die auch ihm nicht erspart blieben. Lektüre, Museumsbesuche, Reisen und der Kontakt mit den Autorinnen und Autoren, den dieser leidenschaftliche Herausgeber nie aufgegeben hatte, beschäftigten ihn während seines langjährigen Ruhestands, den er der geistigen Arbeit widmete. Dieser Mann voller Nuancen und Widersprüche, der skeptisch und gleichzeitig auch Neuem gegenüber offen war, hat möglicherweise nicht selten andere Menschen aus der Fassung gebracht. Während der schönen Trauerfeier in der Friedhofskapelle von Thun, deren Einzelheiten er selbst festgelegt hatte, wurden die verschiedenen Facetten seiner Persönlichkeit ein letztes Mal gut zum Ausdruck gebracht. Von der Schwere der Materie und ihren ehernen Gesetzen, die aber auch im Widerspruch zum geheimnisvollen belebenden Geist dieser Materie stehen, wurden die Trauergäste durch den heiteren Ernst von zwei Chorälen von Bach, die herzzerreissende Zartheit des Stücks «Der Tod und das Mädchen» von Schubert und ein Gedicht von Rainer-Maria Rilke in den entmaterialisierten Raum entführt... Wir werden diesen «honnête homme» (ehrbaren Mann), wie man im Zeitalter der Aufklärung sagte, in guter und dankbarer Erinnerung behalten.

François-X. Deschenaux, Generalsekretär der FMH von 1987-2001 